\title{
The Prognostic Significance of Protein-energy Malnutrition in Geriatric Patients
}

\author{
REGULA MÜHLETHALER, ANDREAS E. STUCK, \\ CHRISTOPH E. MINDER, BRIGITTE M. FREY
}

\section{Summary}

Although it has been shown that protein-energy malnutrition is a predictor of adverse outcome in geriatric patients, it is unclear whether this is due to underlying disease or disability, or whether malnutrition is an independent outcome predictor. To clarify the predictive role of malnutrition, we analysed the 4.5-year mortality and living location follow-ups of 219 geriatric patients admitted to a geriatric assessment unit. Prevalence of anthropometric and serological malnutrition indicators were between $13.7 \%$ and $39.8 \%$ at hospital admission. In bivariate models, prealbumin, subnormal arm muscle area, and subnormal body weight were predictors of mortality and survival at home. On the other hand, albumin, transferrin, and triceps skin-fold thickness did not predict these outcomes. In multivariate models the hazard ratio (HR) of 4.5-year mortality remained significant with an HR of 1.8 (95\% CI 1.3-2.6) for subnormal arm muscle area, and $1.6(95 \% \mathrm{CI}$ 1.0-2.6) for subnormal body weight. Prealbumin was the strongest serological outcome predictor (multivariate mortality HR 1.9, 95\% CI, 1.3-2.8). In these models, subnormal cognitive function, impaired physical function, and creatinine clearance $<30 \mathrm{ml} / \mathrm{min}$ were also associated with increased mortality. Malnutrition did not predict hospital discharge location, but among patients discharged home, those with initial malnutrition had a decreased length of survival at home.

Our findings indicate that certain protein-energy malnutrition indicators are independent risk factors predicting decreased length of overall survival and survival at home in geriatric patients. Physicians should screen actively for this often unrecognized problem and initiate appropriate treatment strategies.

\section{Introduction}

Increasing numbers of older patients are being admitted to acute hospitals in industrialized nations. Clinicians face the challenging task of developing optimal plans for individual treatment and rehabilitation for these patients who often suffer from multiple diseases, while taking account of the limited availability of health-care resources. One major strategy clinicians can use for optimizing patient management is to base their decisions and rehabilitation goals on prognostic information. We chose to evaluate the prognostic value of protein-energy malnutrition because this is a common condition in geriatric patients which is frequently overlooked in clinical practice [1].

In a comprehensive literature review we found seven studies that compared outcomes in older persons with and without protein-energy malnutrition for a followup period of at least 3 months [2-10]. In these studies, some of the selected malnutrition indicators were found to be statistically significant $(p<0.05)$ predictors of mortality or hospital readmission. However, one major methodological issue limits the interpretation of most previous findings presented. Patients with proteinenergy malnutrition are at increased risk of having underlying diseases or functional impairment that favour the development of malnutrition due to increased metabolic demand or decrease in nutrient intake. Thus, the increased mortality risk in malnourished geriatric patients might be related to underlying conditions rather than to malnutrition itself. This means that studies using bivariate statistical models do not indicate whether nutritional assessment adds an independent piece of information to the prognostic equation, or whether information on the conditions underlying malnutrition would be sufficient for predicting outcome in geriatric patients.

We therefore conducted a prospective longitudinal study to determine whether nutritional assessment might add independent prognostic information on long-term survival and quality of life of geriatric patients. 


\section{Methods}

Subjects: All patients aged 65 years and older consecutively admitted to the Geriatrics Evaluation and Management Unit (GEMU), Zieglerspital, Bern, from 1 June to 17 Dec 1987, were enrolled in this study. The study was approved by the University of Bern Ethics Committee. Patients remaining in care for less than 48 hours were excluded. Overall, 219 patients, 69 men and 150 women, with a mean age of 81.6 years (range 66-95 years) fulfilled the study entry criteria. All patients were of 'Caucasian' ethnicity, representative of the unit's locale. The GEMU is a 76-bed acute assessment and rehabilitation unit. Patients are cared for by an interdisciplinary team, including a staff geriatrician, an assistant physician, rehabilitation nurses, physical and occupational therapists, a social worker, a dentist, and a dietician. The majority of the patients come to the GEMU as direct admissions from the community. A minority of patients are transfers from other hospitals or from community nursing homes. Mean length of stay was 50.4 days (range 4-299 days).

Admission: Within 48 hours of hospital admission, a baseline multidimensional geriatric assessment including detailed nutritional assessment was completed on all patients. Nutritional assessment included body weight and height measurement. Percentage average body weight was then calculated by dividing the patient's body weight by the corresponding age- and sex-specific average body weight [11] and multiplying this ratio by 100 . Triceps skin-fold thickness and mid-arm circumference were measured in the right arm midway between the tip of the acromion and the olecranon using a Holtain skin-fold caliper which has a pressure of $10 \mathrm{~g}$ / $\mathrm{mm}^{2}$ of contact surface area over its entire operating range. The same investigator (A.E.S.) performed three measurements and recorded the mean value. Bone-free arm muscle area was calculated based on the Heymsfield equation [1214]. Serum albumin was determined by the bromocresolgreen assay. Prealbumin and transferrin were measured by radial immunodiffusion [15-17].

Cognitive function was assessed by trained physicians using a 30-item mental status questionnaire [18]. Baseline activities of daily living were assessed by the nursing staff on a 0 - to 6 point scale with 0 for independent and 6 for completely dependent function [19]. Creatinine clearance in $\mathrm{ml} / \mathrm{min}$ was calculated using the formula $(140$-age) $\times$ (weight in $\mathrm{kg}$ )/ (serum creatinine in $\mu \mathrm{mol} / \mathrm{l} \times 0.814$ ) for male patients. For women, this formula was multiplied by 0.851 . In all patients, clinical diagnoses were listed according to the ICD9 revised classification criteria. Preadmission residence status was determined for all patients.

Follow-up: Survival status and living location of all 219 patients were determined by telephone follow-up, hospital records, nursing home administrative data, and Federal Office of Statistics records 4.5 years after hospital admission. Date of death or date of nursing-home admission were recorded for all patients who were no longer living in the community.

Variable definitions: All continuous or score variables were dichotomized and assigned 0 for normal, and 1 for abnormal values. We used the following cut-off criteria for definition of abnormal values: percentage average body weight $<80 \%$, anthropometric measurements $<5$ th percentile (according to age- and sex-specific values assuming medium frame $[12,13]$, albumin $<30 \mathrm{~g} / \mathrm{l}$, prealbumin $<150 \mathrm{mg} / \mathrm{l}$, transferrin $<2 \mathrm{~g} / \mathrm{l}$, mini-mental status $<20$ (out of 30 ) points, basic activities of daily living one or more dependencies (out of six domains), and creatinine clearance $<30 \mathrm{ml} / \mathrm{min}$. The presence of a clinical diagnosis was coded as 1 , its absence as 0 . The dependent variables were mortality, hospital discharge disposition and length of survival at home. For the mortality analysis, the number of days survived were used, with censoring of values greater than 1643 days for surviving patients. Discharge disposition was coded as 1 for discharge home and as 0 for discharge not home (i.e. death, nursinghome admission). For patients discharged home we determined the length of survival at home as the total number of days with residence status in the community (i.e. not dead, not residing in nursing home).

Statistical analyses: For purposes of analysis, proportional hazard survival analysis and logistic regression were used [20, 21]. Each of the six selected malnutrition indicators was analysed as a univariate mortality predictor. Then, we selected the one protein-malnutrition and the one energymalnutrition indicator best predicting mortality for further multivariate analysis. We calculated two multivariate predictive models for each of the three dependent variables (i.e. survival, discharge home, home survival). The first multivariate model included the two selected malnutrition indicators plus the variables defining medical diagnoses (overall nine independent variables). In the second model we combined the two malnutrition indicators with physical function, cognitive function, renal function, and living-alone status. This two-model approach was necessary because our sample size did not permit us to include all independent variables into one single regression model.

\section{Results}

At hospital admission, $35.9 \%$ of the patients had an abnormally low arm-muscle area, and $20-40 \%$ of patients had serological indicators of protein malnutrition (Table I). Body weight was below $80 \%$ of age- and sex-specific average values in $13.7 \%$, and triceps skinfold thickness was subnormal in $30.3 \%$ of patients, suggesting energy malnutrition. One year after hospital admission, 55 of the 219 patients (25.1\%) had died, 78 $(35.6 \%)$ were residing in a nursing home, and 86 were living in the community $(39.3 \%)$. Four and a half years after hospital admission, $148(67.6 \%)$ had died, 35 $(16.0 \%)$ were residing in a nursing home, and 36 $(16.4 \%)$ were living in the community.

Table I lists the univariate prediction of mortality with the six selected malnutrition indicators. Abnormally low arm-muscle area, subnormal serum prealbu$\mathrm{min}$, and decreased average body weight were strongly associated with increased mortality. On the other hand, serum albumin, transferrin, and triceps skin-fold thickness did not show such a statistically significant association. Accordingly, we selected subnormal arm muscle area as the indicator of protein malnutrition, and low average body weight as the indicator of energy malnutrition for inclusion in the multivariate analyses.

The results of the multivariate models predicting 4.5-year mortality are depicted in Table II. In the multivariate analysis which included functional variables, the mortality hazard ratio was significantly increased for patients with a subnormal arm-muscle area $(1.8 ; 95 \%$ CI $1.3-2.6 ; p=0.001)$, and showed a statistical trend for patients with subnormal average body weight $(1.6 ; 95 \%$ CI $1.0-2.6 ; p=0.06)$ (Table II). 
Table I. Univariate prediction of 4.5 -year mortality with malnutrition indicators $(\mathrm{n}=219$ geriatric patients)

\begin{tabular}{lll}
\hline Variable & $\begin{array}{l}\text { Prevalence } \\
(\%)\end{array}$ & $\begin{array}{l}\text { Hazard ratio } \\
(95 \% \mathrm{CI}) \ddagger\end{array}$ \\
\hline $\begin{array}{l}\text { Indicators of protein malnutrition: } \\
\text { Arm muscle area }<5 \text { th percentile }\end{array}$ & 35.9 & $2.1(1.5-2.9)$ \\
Serum albumin $<30 \mathrm{~g} / \mathrm{l}$ & 27.5 & $1.3(0.9-1.8)$ \\
Serum prealbumin $<150 \mathrm{mg} / 1$ & 20.3 & $2.1(1.4-3.0)$ \\
Serum transferrin $<2 \mathrm{~g} / 1$ & 39.8 & $1.1(0.8-1.5)$ \\
Indicators of energy malnutrition: $\dagger$ & & 0.0001 \\
Average body weight $<80 \%$ of normal & 13.7 & $2.0(1.4-3.1)$ \\
Triceps skin-fold thickness $<5$ th percentile & 30.3 & $1.1(0.8-1.6)$ \\
\hline
\end{tabular}

CI: confidence interval.

- Thirteen subjects with incomplete data.

† One subject with incomplete data.

¥ Hazard ratio $>1$ indicates higher mortality risk in patients with presence of malnutrition indicator.

The difference in the $p$ value between these two malnutrition indicators was presumably mainly due to the smaller number of subjects with subnormal average body weight (prevalence 13.7\%) as compared to subnormal arm-muscle area $(35.9 \%)$. Similarly, in the multivariate analysis including medical diagnoses the predictive values of subnormal arm-muscle area and of low average body weight were statistically significant.

Subnormal cognitive function and impaired physical function, but neither malnutrition indicators nor renal dysfunction, predicted the patient's discharge location. Furthermore, patients living alone were less likely to be discharged home although this finding was not statistically significant (OR $0.5,95 \%$ CI $0.2-1.1$; $\mathrm{p}=0.09$ ).

Finally we tested the models predicting length of survival at home for the subgroup of patients who were discharged home (Table III). In the model including functional variables, malnutrition and cognitive dysfunction were the strongest predictors of decreased length of home survival. In the alternative model including medical diagnoses (not shown on table), malnutrition was also associated with a decreased length of home survival.

We conducted several sensitivity analyses to test the $a$ priori decisions of this study. First, we changed the cutoffs for the definition of impaired physical and abnormal cognitive function, added age and sex as variables to the multivariate equations, and finally repeated all analyses after exclusion of patients with malignancies. In most cases, this led to a widening of the confidence intervals, but did not change our conclusions. Next, we replaced the predictive variable 'arm-muscle area' with the variable 'serum prealbumin' in all multivariate equations because prealbumin was also a strong univariate mortality predictor in our analysis. In the multivariate models which included functional diagnoses, low serum prealbumin significantly predicted mortality (hazard ratio $1.9,95 \%$ CI $1.3-2.8, \mathrm{p}=0.002$ ), but not length of home survival (hazard ratio $1.1,95 \%$ CI $0.6-1.9$, $\mathrm{p}=0.3)$.

\section{Discussion}

This longitudinal study revealed that certain signs of protein-energy malnutrition are strong independent predictors of survival and living location of geriatric patients. Our results show that a geriatric patient's prognosis is determined by his or her physical function, cognitive function, social network, morbidity, and nutritional status. In malnourished patients, both length of overall survival and length of survival at home is decreased.

The findings must however be regarded in the light of the possible methodological limitations of this study. Although alternative methods of variable definition or statistical analysis could have been used, we tried to use a priori rules based on research hypotheses and clinical relevance. We selected the variables based on their hypothesized predictive ability and chose dichotomous

Table II. Multivariate prediction of 4.5-year mortality ( $n=219$ geriatric patients*)

\begin{tabular}{lll}
\hline Variable & $\begin{array}{l}\text { Hazard ratio } \\
(95 \% \mathrm{CI}) \dagger\end{array}$ & $\mathrm{p}$ \\
\hline Arm muscle area $<5$ th percentile & $1.8(1.3-2.6)$ & 0.001 \\
$\quad \begin{array}{ll}\text { Average body weight }<80 \% \text { of } \\
\quad \text { normal }\end{array}$ & $1.6(1.0-2.6)$ & 0.06 \\
Subnormal cognitive function & $1.5(1.1-2.2)$ & 0.02 \\
Impaired physical function & $1.5(1.0-2.2)$ & 0.02 \\
Creatinine clearance $<30 \mathrm{ml} / \mathrm{min}$ & $1.6(1.1-2.3)$ & 0.009
\end{tabular}

- Two subjects with missing data.

$\dagger$ Hazard ratio $>1$ indicates higher mortality risk in patients with abnormal parameter. 
Table III. Multivariate prediction of 4.5-year home survival of geriatric patients

\begin{tabular}{lll}
\hline Variable & $\begin{array}{l}\text { Hazard ratio } \\
(95 \% \mathrm{CI})\end{array}$ & p-value \\
\hline $\begin{array}{l}\text { Arm muscle area < 5th percentile } \\
\text { Average body weight < 80\% of }\end{array}$ & $1.7(1.1-2.7)$ & 0.02 \\
$\quad$ normal & $1.7(0.9-3.1)$ & 0.08 \\
$\begin{array}{l}\text { Subnormal cognitive function } \\
\text { Impaired physical function }\end{array}$ & $1.7(1.1-2.5)$ & 0.02 \\
$\begin{array}{l}\text { Creatinine clearance }<30 \mathrm{ml} / \mathrm{min} \\
\text { Living alone before hospital }\end{array}$ & $1.2(0.7-1.9)$ & 0.17 \\
$\quad$ admission & $1.0(0.6-1.6)$ & 0.95 \\
\hline
\end{tabular}

- Cox proportional hazard survival analysis; sample includes 125 geriatric patients discharged home; two subjects with incomplete data.

Hazard ratio $>1$ indicates shorter length of survival at home for subjects with abnormal parameter.

variable cut-offs rather than scaled or continuous variables because dichotomous variables are more convenient for use in clinical practice. We then developed an explicit plan for statistical analysis based on the main research questions. This approach has the advantage of limiting the number of statistical tests and thus of avoiding exploratory statistical analyses with the problem of multiple comparisons. Finally, we performed several sensitivity analyses and found that changing some of the assumptions would not have affected our conclusions.

Each longitudinal study has to address the issue of missing data or loss of individuals over time. In this study, we had missing information on admission anthropometric status for two $(0.9 \%)$ and on admission serological variables for $13(5.9 \%)$ of the 219 subjects. We were able to determine exact 4.5-year follow-up information on survival and residence location over time for all 219 subjects (no missing data). Therefore, it is unlikely that missing information has affected our results.

The finding that malnutrition improves outcome prediction for hospitalized geriatric patients has major clinical implications. Clinicians who have better information on a patient's prognosis have been shown to alter patient management [22]. In the case of malnutrition, the first step is better clinical recognition of this often unrecognized problem. It has been shown that more than $50 \%$ of severe cases of protein-energy malnutrition may go undetected in hospitalized geriatric patients $[1,23]$. Once the problem is recognized, clinicians must decide on appropriate management for malnutrition. For a minority of malnourished geriatric patients with very poor prognosis, reduction in therapeutic efforts may be indicated. Most malnourished geriatric patients however would probably benefit from nutritional intervention and management of conditions underlying malnutrition $[24,25]$. For example, one of the main conditions leading to malnutrition in geriatric patients is depression, which is a highly treatable condition.

In conclusion, malnutrition is a major independent predictor of adverse outcome in elderly hospitalized patients. This increased risk is not explained by the increased mortality risk associated with diseases or disabilities underlying malnutrition.

\section{Acknowledgements}

This project was supported by a grant from the Swiss National Science Foundation (Grant No. 4032-35637 and No. 32-31048-91) and the Foundation for the Support of Research at the University of Bern.

The paper was presented, in part, at the Annual Meeting of the Gerontological Society of America, New Orleans, November 1993.

\section{References}

1. Mowe M, Bohmer T. The prevalence of undiagnosed protein-calorie undernutrition in a population of hospitalized elderly patients. F Am Geriatr Soc 1991;39:108992.

2. Dwyer JT, Coleman KA, Krall E, et al. Changes in relative weight among institutionalized elderly adults. $\mathcal{F}$ Gerontol 1987;42:246-51.

3. Ferguson RP, O'Connor P, Crabtree B, Batchelor A, Mitchell J, Coppola D. Serum albumin and prcalbumin as predictors of clinical outcomes of hospitalized elderly nursing home residents. I Am Geriatr Soc 1993;41:54549.

4. Friedman PJ, Campbell AJ, Caradoc-Davies TH. Prospective trial of a new diagnostic criterion for severe wasting malnutrition in the elderly. Age Ageing 1985;14:149-54

5. Friedman PJ, Campbell AJ, Caradoc-Davies TH. Hypoalbuminemia in the elderly is due to disease not malnutrition. F Clin Exp Gerontol 1985;7:191-203.

6. Larsson J, Unosson M, Ek AC, Nilsson L, Thorslund S, Bjurulf P. Effect of dietary supplement on nutritional status and clinical outcome in 501 geriatric patients-a randomised study. Clin Nutr 1990;9:179-84.

7. Mattila $\mathrm{K}$, Haavisto $M$, Rajala $S$. Body mass index and mortality in the elderly. Br Med F 1986;292:867-8.

8. Sullivan DH. Risk factors for early hospital readmission in a select population of geriatric rehabilitation patients: the significance of nutritional status. $\mathcal{F} \mathrm{Am}$ Geriatr $S o c$ 1992;40:792-8.

9. Sullivan DH, Walls RC, Lipschitz DA. Protein-energy undernutrition and the risk of mortality within $1 \mathrm{y}$ of hospital discharge in a select population of geriatric rehabilitation patients. Am f Clin Nutr 1991;53:599-605.

10. Volkert D, Kruse W, Oster P, Schlierf G. Malnutrition in geriatric patients: diagnostic and prognostic significance of nutritional parameters. Ann Nutr Metab 1992;36:97112.

11. Master AM, Lasser RP, Beckman BA. Tables of average weight and height of Americans aged 65 to 94 years. IAMA 1960;172:658-62.

12. Frisancho AR. New standards of weight and body composition by frame size and height for assessment of nutritional status of adults and the elderly. Am $\mathrm{J}$ Clin Nutr 1984;40:808-19.

13. Falciglia G, O'Connor J, Gedling E. Upper arm 
anthropometric norms in elderly white subjects. $\mathcal{I} \mathrm{Am}$ Diet Assoc 1988;88:569-74.

14. Heymsfield SB, McManus C, Smith J, Stevens V, Nixon DW. Anthropometric measurement of muscle mass: revised equations for calculating bone-free arm muscle area. Am $\mathcal{f}$ Clin Nutr 1982;36:680-90.

15. McFarlane $\mathrm{H}$, Ogbeide MI, Reddy S. Biochemical assessment of protein-calorie malnutrition. Lancet $1969 ; \mathbf{i}: 392-4$.

16. Frey BM, Mordasini R, Frey FJ, Wegmueller E, Schlierf $G$, Hodler J. Dysproteinaemia during total fasting. Metabolism 1979;28:363-8.

17. Shetty PS, Watrasiewicz KE, Jung RT, James WPT. Rapid-turnover transport proteins: an index of subclinical protein-energy malnutrition. Lancet 1979;2: 230-2.

18. Jacobs JW, Bernhard MH, Delgado A, Strain JJ. Screening for organic mental syndromes in the medically ill. Ann Intern Med 1977;86:40-6.

19. Katz S, Ford AB, Moskowitz RW, Jackson BA, Jaffe MW. Studies of illness in the aged: the index of ADL. JAMA 1963;185:914-19.

20. Andersen PK. Multistate models in survival analysis: a study of nephropathy and mortality in diabetes. Stat Med 1988; 7:661-70.

21. Concato J, Feinstein AR, Holford TR. The risk of determining risk with multivariate models. Ann Int Med 1993;118:201-10.
22. Murray LS, Teasdale GM, Murray GD, et al. Does prediction of outcome alter patient management? Lancet 1993;341:1487-91.

23. Morley JE. Why do physicians fail to recognize and treat malnutrition in older persons? $f \mathrm{Am}$ Geriatr Soc 1991;39:1139-40.

24. Dempsey DT, Mullen JL, Buzby GP. The link between nutritional status and clinical outcome: can nutritional intervention modify it? $A m$ f Clin Nutr 1988;47:352-6.

25. Stuck AE, Siu AL, Wieland GD, Adams J, Rubenstein LZ. Comprehensive geriatric assessment: a meta-analysis of controlled trials. Lancet 1993;342:1032-6.

\section{Authors' addresses}

R. Mühlethaler, A. E. Stuck*

Department of Geriatrics and Rehabilitation, Zieglerspital, Morillonstr. 75,

3001 Bern, Switzerland

C. E. Minder

Department of Social and Preventive Medicine,

B. M. Frey

Division of Nephrology,

University of Bern, Switzerland

Received in revised form 30 fuly 1994 